\title{
NEW SOURCES OF ENERGY
}

T THE United Nations Conference on "New Sources of Energy" was convened for the exchange of experiences and new ideas on recent progress in the applications of solar energy, wind power and geothermal energy, and held in Rome during August 21-31. The term 'new' is not perhaps the best description of these sources of energy which have been used by humanity for many centuries, and is used to emphasize that their development has been largely ignored or regarded as unecono. mical in the past but that they should now be included in any survey of power resources. These three forms of energy are very different in their characteristics; a geothermal energy source is a gift for any nation fortunate enough to possess such a site, for although there are many problems involved in harnessing this form of energy, its utilization follows well-established procedures. Solar and wind energies are ubiquitous, though varying in intensity in different localities and at different times; they are both 'low intensity' sources having a maximum energy flux of the order of $1 \mathrm{~kW} . / \mathrm{m} .{ }^{2}$. The latter, however, is in the form of mechanical energy for which Nature has paid the toll of the Carnot cycle efficiency, while the former is in the form of heat, and mankind must pay the toll to convert this to mechanical or electrical energy. Consequently, although the conversion of solar radiation to electrical power on a small scale would be advantageous, the major form of utilization should be as heat at low or high temperatures as required.

It is not possible to make detailed comment here on the technical proceedings at a conference attended by some 650 delegates from more than fifty countries and at which some 250 papers were presented, about half being on applications of solar energy. All the papers were summarized by rapporteurs in sections; these reports were discussed later and a final summary was given at the concluding session for each form of energy under consideration. 'Two visits were arranged during the conference. One was to a demonstration of a solar power plant, $2-5 \mathrm{~kW}$. capacity, designed by the National Physical Laboratory of Israel. This uses air-inflated plastic mirrors and covers in the form of cylinders about $12 \mathrm{~m}$. long which are aligned east and west, and only need moving occasionally to allow for the seasonal change in the position of the Sun. Steam is produced at a temperature of $150^{\circ} \mathrm{C}$. and the heat transferred in a storage vessel to vaporize an organic working fluid which is expanded in an impulse turbine, condensed and returned to the heat exchanger. This design has been reduced to the simplest essentials and has an estimated cost of 1,000 dollars per $\mathrm{kW}$. installed, and a power cost of 5 cents per $\mathrm{kW}$. hr. based on 6 per cent interest rate and 15 years life. The other visit, of contrasting nature, was to the geothermal station of Larderello. This power system, in use before the Second World War, has now been extended to a capacity of $2 \times 10^{9}$ $\mathrm{kW}$. hr. annually, using steam at an average pressure of 5 atmospheres absolute and a temperature of $200^{\circ} \mathrm{C}$. The first impression is the unusual sight of gigantic cooling towers rising from surrounding countryside, with a relatively low power-house and a maze of snake-like pipes conveying steam from the distributed bore-holes. Use of geothermal steam is complicated by the high gas and mineral content of the steam, so that most of the power stations operate by heat transfer to a pure water circuit from which the steam is passed. to the turbines. This simplifies the gas removal problem and provides for effective recovery of the minerals, mainly boron compounds. Conference papers were presented on the recent developments in the use of geothermal power in New Zealand and Iceland, as well as prospective applications in Japan, South America and other volcanic zones.

Wind-power units of small output are well established in agricultural regions. The problems involved in larger units of $100-500 \mathrm{~kW}$. which could generate electricity for a grid supply are still under investigation, but the tendency would appear to be towards a direct-drive propeller unit geared up to the generator by mechanical or hydraulic transmission and with automatic voltage control.

The papers on solar energy applications covered many fields, such as water and house heating, crop drying, distillation, power production by thermal cycles, refrigeration, air conditioning and cooking. The direct conversion of radiation to electricity by thermocouples, photo-voltaic cells and thermionic devices was also discussed, and recent developments in solar furnaces. Details of these processes were described more fully in my report on the World Symposium on Applied. Solar Energy, Arizona, 1955 (Nature, 177, 110;1956). Since that date there has been development in new designs and improved equipment, especially as regards economical construction, but no really new principles have emerged. The number of large-scale installations for water heating and distillation at present existing remains very small, and there is still insufficient detailed information available to select the most satisfactory designs for various purposes. Most of the designs in the fields mentioned above have been developed independently, and are still in the experimental stage. Large-scale commercial developments seem limited to water heaters in Israel, and some large. area solar-stills in the United States. One of the proposals given prominence at the conference was that a series of experimental stations should be established in various countries where the scaling up from the experimental models to the larger industrial installations could be developed and in this connexion mention should be made of the Brace Experimental Station at Barbados, West Indies, recently established by McGill University. The extensive funds available for research on space travel and artificial satellite powering will make possible the development of many schemes for the direct production of power from solar radiation which can be adapted for terrestrial use.

Perhaps it will be more profitable in the space available to discuss the economic and social implications of solar energy utilization. Much of the discussion at the conference concerned the under-developed nations, which might be described more politely as non-industrial, and how these could be helped by the industrial nations. One possible procedure suggested would be for the industrial countries to manufacture and sell equipment to the non-industrial countries, 
but individuals could not afford to purchase such equipment without a national subsidy in the first instance. The preferred alternative would be for the industrial countries to develop very simple designs of equipment which could be made in the country where required and thereby establish village industries. The first stage might well be along communal lines in villages, for baths, refrigeration and electricity generation, rather than attempting to accomplish these for individual dwellings. The importance of simplicity was emphasized, since in solar appliances the capital cost per unit of energy collected is more significant than the thermal efficiency of conversion. The sociological feature is the difficulty of introducing a new method of doing something already accomplished by other means, for example, to replace refuse-burning cookers by solar cookers, but where the application is completely new, as for electricity generation or refrigeration, there is not the resistance of tradition.

As regards industrial countries, solar energy can only be integrated with other energy sources, and water heating is the most feasible application. The prospects of success are greatest in the Mediterranean countries, decreasing but not necessarily being nonexistent in the more temperate countries. Much consideration was given to the assessment of potential resources in all the fields of energy considered. These data are particularly lacking as regards solar radiation and a much closer network of recording stations is required to assess the availability on a micro-climatic basis.

The final conclusions would appear to be:

Geothermal power is analogous to hydro-power, and obviously should be developed in the few localities where such sourees exist, provided that the power can be transmitted to centres of population. Wind- power is an established factor in agricultural areas. but development is needed before large wind-power generators can be constructed. Utilization of solar energy is the most difficult of all to establish. Protagonists must have faith in the possibilities, some of which are not yet proved. Similar situations have. however, arisen in other technologies now fully established and justified, for example, space travel. where the initial difficulties have eventually been overcome as unforeseen developments occurred. The urgent needs are international co-operation to establish satisfactory designs of equipment and the training in Europe and the United States of personnel from the user nations who can return to promote investigations in their own countries.

The general impression is that the development in six years is not as great as would have been expected. It is, however, encouraging to find that there are many people of high academic ability in various countries who have enough faith to devote their whole, or at least a considerable proportion, of their time to the attainment of a deeper knowledge of the underlying principles of all these sources of energy and in particular of solar energy devices, in order to raise the existing standard of living in under-developed countries. Co-ordinated planning during the next six years should promote a significant increase in applications.

Long-term predictions for the future are necessarily uncertain, but there is no doubt that energy demands will grow more rapidly than the world population. which is expected to double by the year 2000, and that all sources of energy should be actively investigated and integrated. The conference and discussions arising will undoubtedly promote these objectives. and lead to more successful international co-operation in future developments. H. HerwooD

\section{MICROWAVE MEASUREMENT TECHNIQUES}

\begin{abstract}
A CONFERENCE on the general subject of microwave measurements was held at the Institution of Electrical Engineers during September 6-8. A large audience of scientists and engineers from many countries assembled to consider some fifty papers covering all aspects of modern microwave measurement.

In his introductory lecture, Prof. H. E. M. Barlow, of University College, London, stated that microwave measurement techniques could, be grouped broadly under the following headings: measurements using field probes; measurements depending on resonance arrangements; attenuation and phase shift measurements; noise measurements and power measurements; and that the general limits of accuracy of microwave measurements at the present day were of the order of $\pm 0 \cdot 1$ per cent for impedance measurements, \pm 1 per cent for power measurements, and about $\pm 0.01 \mathrm{db}$. up to $3 \mathrm{db}$. for attentuation measurements.

Subsequent sessions of the conference considered most of these groups in detail.

Prof. Barlow also described two new devices utilizing the Hall effect for microwave power measurement. In the first, a thin indium arsenide crystal is rotated continuously in a wave-guide. The resulting Hall E.M.F. in the crystal is thus modulated at the
\end{abstract}

rotation frequency, unlike the parasitic thermoelectric and rectified E.M.F.s occurring at the crystal contacts. from which it can therefore be separated by a filter. The second device was demonstrated, and comprised an array of Hall crystals in cascade which could be used to measure high-power densities in free space. The multiplicity of crystals helps to cancel out the unbalanced rectifier effects occurring at the contacts.

A supporting paper by R. E. Larson of the Boulder Laboratories of the U.S. National Bureau of Standards outlined the calibration facilities offered by the Electronic Calibration Center of the Bureau. These are ultimately intended to cover the measurement of power, impedance, frequency, attenuation and noise over the full frequency-range $300-40,000 \mathrm{Mc}$. $\mathrm{s}$.

An interesting paper by Prof. C. Süsskind and P. O. Vogelhut, under the title "Cavity-perturbation Measurements of the Effect of Microwave Radiation on Proteins", described experiments concerned with the biological effects of microwave radiation on living animals. Irradiating power densities of the order of $0.1 \mathrm{~W} . / \mathrm{cm}^{2}$ produce significant changes of body temperature in mice, and accordingly the 'tolerance' level for human beings is accepted as $0.01 \mathrm{~W} . / \mathrm{cm}^{2}$. Apart from the heating effect, microwave irradiation causes other biological 